\title{
Cystic fibrosis screening in the newborn
}

\author{
P. G. ROBINSON and R. B. ELLIOTT \\ From the Department of Paediatrics, School of Medicine, University of Auckland, New Zealand
}

Robinson, P. G., and Elliott, R. B. (1976). Archives of Disease in Childhood, 51, 301. Cystic fibrosis screening in the newborn. A new technique of measuring stool enzyme activity on dry specimens of faeces from newborn children at 4-5 days of age has detected 3 cases of cystic fibrosis in the first 6000 tests. No known cases of cystic fibrosis have been missed. Additionally, one case of pancreatic achylia of at least 4 months' duration has been detected. It is proposed that the detection of cystic fibrosis by this technique is sufficiently practical to be acceptable as a worthwhile newborn screening programme.

The screening test has been in use in Auckland for over a year and is now being set up in Hamilton, Wellington, and Dunedin (New Zealand), and Sydney (Australia).

Cystic fibrosis remains the commonest genetically determined disease of serious nature in children of Caucasian origin. In New Zealand it appears to affect about 1 in 3500 newborns, and accounts therefore for about 20 new cases per year in this country. If early treatment is helpful in preventing the often fatal complications of the disease (see below), it would be worthwhile establishing a reliable and cheap newborn detection programme. Previous attempts to diagnose the disease are either too expensive for screening (e.g. sweat salt concentrations) or lack specificity (gelatin digestion by stool). Recently meconium albumin concentration has been used (Prosser et al., 1974). When 'dipstix' techniques are used (e.g. Prosser et al., 1974) the results are open to observer error, and lack of quality control. The electrophoresis of proteins (Ryley et al., 1974) requires special laboratory facilities and is not inexpensive. Our own recently described technique of specific stool enzyme assay (Robinson and Elliott, 1974) has been modified for a mass screening programme. The initial results of this programme are reported.

\section{Material and methods}

All patients born at two major maternity hospitals in Auckland (National Women's and St. Helen's) from August 1974 to June 1975 had a stool sample collected after day 4 on the specially prepared cards (see Fig.). These cards were forwarded approximately twice weekly to our laboratories. Retesting of all those showing a level of enzymes less than normal was carried

Received 14 July 1975.

\section{CYSTIC FIBROSIS SCREENING}

\section{School of Medicine Department of Paediatrics 85 Park Road Auckland}

Name

D of $B$

Hospital

Hospital No.

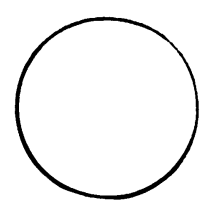

Completely cover circle with faeces.

Fold paper on dotted line over sample. Press firmly and staple down.

Fig.-Faeces collection card $(6 \times 11 \mathrm{~cm})$ made from blotting paper with plastic film stapled on the back. 301 
out using the same technique. If the stool sample again showed less than normal concentrations of enzyme, a formal quantitative assay of the enzymes was carried out by a simple technique devised in our laboratory (Robinson, Smith, and Elliott, 1975). If still below normal values, a quantitative sweat test (see below) was performed.

A disc (approximately $6 \mathrm{~mm}$ in diameter) was punched from each faeces sample into an appropriately numbered hole in a dimple tray (corresponding to the last two digits of the serial number stamped on the card). Included in each set of tests were dimples containing $0.5 \mathrm{ml}$ of standard enzyme $(1 \mathrm{mg} / \mathrm{ml})$ and the three working dilutions $(1: 20,1: 200$, and $1: 2000)$. A mixture of buffer, indicator, and substrate solutions was made (in the proportions of $6: 2: 1$ for the trypsin assay) and $p \mathrm{H}$ adjusted to 8.2 with $0.1 \mathrm{~mol} / 1 \mathrm{NaOH}$. This was then added in $0.9 \mathrm{ml}$ aliquots to each dimple. The trays were each briefly mixed on a vortex mixer and then incubated at $37^{\circ} \mathrm{C}$ until the weakest dilution of standard enzyme started to change colour (from purple to yellow). At this stage the colour in each of the holes was noted and the result entered in the book ( + , change; $\times$, no change; and \pm , little change).

A chymotrypsin assay was then done on those samples which showed little or no change in colour, with 5-10 randomly selected samples for controls and a set of standard enzyme solutions. The method was as for trypsin but different buffer and indicator solutions were used and double the quantity of substrate (ATEE) was added. Retest samples were then requested on those babies showing abnormal trypsin and chymotrypsin levels. Quantitative analyses were carried out using our previously reported method (Robinson et al., 1976).

A cystic fibrosis screening card (Fig.) was completed and attached to the baby's chart at birth. On the fifth postnatal day a pea-size faecal sample was smeared on the circle on the card, which was folded, stapled down, and then forwarded to the screening laboratory.

If a specimen showed abnormal enzymes, a retest request with a screening card marked 'Retest' was sent to the nurse at the hospital where the baby was born, with details of name, date of birth, test date, and hospital number. Other details requesıed were gestational age, birthweight, the race of the parents, and any medication being given (pancreatic enzyme supplements interfere with the test). These details were sent to this laboratory by the nurse, who also forwarded the retest request, with the mother's address, to the District Nursing Division of the Auckland Extramural Hospital. The district nurse visited the mother and arranged for a repeat specimen to be put on the card which was then sent to the screening laboratory. Forms were forwarded through the hospital nurse to the district nurses who arranged collection and delivery of a 1-2 $\mathrm{g}$ sample of faeces. Where possible the sample was frozen soon after collection and delivery to the laboratory was usually within 24 hours.

Sweat testing. The apparatus and method of Gibson and Cooke (1959) was used. Sweat was collected on prewashed $4.5 \mathrm{~cm}$ square Whatma No. 42 filter paper for 3 consecutive 10 -minute period and the sweat sodium concentration determined $b$ atomic absorption spectroscopy. As pointed out b Schwarz and Thaysen (1956) the sweat sodium concen tration is very dependent on sweat rate and so all ou results are expressed as $\left(\mathrm{Na}^{+}\right)$in $\mathrm{mEq} / \mathrm{l}$ at a given swe rate in $\mathrm{g} / \mathrm{m}^{2}$ per min. Three periods of collection wer used because, as stated by Schwarz and Thayse (1956), results obtained at sweat rates of less tha $5 \mathrm{~g} / \mathrm{m}^{2}$ per min may be anomalous and the results fo the first collection period are atypical. Typical result obtained in our laboratory over a period of about 1 yea are: cystic fibrosis patients (32) sodium 93.4 \pm 18 . $\mathrm{mEq} / \mathrm{l}$ at sweat rate $6 \cdot 2 \pm 1 \cdot 4 \mathrm{~g} / \mathrm{m}^{2}$ per min; control (15) sodium $12.4 \mathrm{mEq} / 1$ at sweat rate $6.2 \pm 1.6 \mathrm{~g} / \mathrm{m}$ per min.

When a screening card arrived at the laboratory th following data were recorded in a book: surname c mother, date of birth, hospital number, and date $c$ specimen. All samples were stamped with an automati numerator (ENM Model 4513) and the serial numbe recorded to give a continuous record of the number $c$ tests carried out. Retest samples were appropriatel marked and the page ruled off when each batch of test was carried out. Columns for results of trypsin an chymotrypsin assays and comments were included.

All abnormal results were stored on a minicompute system (Wang 2200B computer, 2216 CRT, 2217 Tap Cassette, 2222 keyboard, 2201 output writer) whic kept a record of abnormal retests and quantitativ stool assay results, as well as prepared form letters fc retest requests and quantitative stool sample request: Statistical data (number of tests, etc.) were also store and automatically updated. Quantitative stool enzym analyses, which were run as laboratory routine 0 material from many sources, were kept separately.

Trizma base (trishydroxymethylaminomethan TRIS, Sigma T 1503), Trizma-HCl (TRIS-HC Sigma T 3253), p-tosyl-L-arginine methyl ester (TAMF Sigma T4626), N-acetyl-L-tyrosine ethyl ester (ATEF Sigma A6751), sodium chloride and calcium chlorid dihydrate (LR), bromothymol blue (Sigma B0128 phenol red (Sigma P4633), neutral red (George 1 Gurr Ltd. 22676), trypsin (Sigma T0134), and o chymotrypsin (Sigma C4129), were obtained from th sources indicated.

Sample cards (Fig.) were prepared from blotting pape with polyethylene film $(35 \mu \mathrm{m})$ stapled on as a backin! Tests were carried out in clear plastic, 96-hole dimp] trays (Linbro Co., U.S.A.).

Trypsin. Buffer $(p \mathrm{H} \mathrm{8} \cdot 2,0 \cdot 005 \mathrm{~mol} / \mathrm{l})$ was prepare by dissolving TRIS-HCl $(0.354 \mathrm{~g})$, TRIS $(0.334$ sodium chloride $(2 \cdot 34 \mathrm{~g})$, and calcium chloride dihydrat $(2.94 \mathrm{~g})$ in a litre of water. Substrate solution containe TAME $(2.075 \mathrm{~g})$ in $50 \mathrm{ml}$ buffer. Indicator solutio was made by mixing $5 \mathrm{ml} 0.2 \%$ bromothymol blue an $5 \mathrm{ml} 0.2 \%$ phenol red (both in $50 \%$ ethanol) wit $50 \mathrm{ml}$ buffer. Standard enzyme solution was $1 \mathrm{mg} / \mathrm{r}$ buffer with working dilutions (prepared daily) of $1: 2($ $1: 200,1: 2000$ in buffer. 
Chymotrypsin. Buffer ( $p \mathrm{H} \mathrm{7.8,0.005} \mathrm{mol/1)} \mathrm{was}$ prepared by dissolving TRIS- $\mathrm{HCl}(0.532 \mathrm{~g})$, TRIS $(0.198 \mathrm{~g})$, sodium chloride $(2.925 \mathrm{~g})$, and calcium chloride dihydrate $(0.735 \mathrm{~g})$ in a litre of water. Substrate solution was made by dissolving ATEE $(0.452 \mathrm{~g})$ in $25 \mathrm{ml}$ methanol and making up to $50 \mathrm{ml}$ with buffer. Indicator solution was prepared by mixing $5 \mathrm{ml} 0.2 \%$ bromothymol blue and $5 \mathrm{ml} 0.2 \%$ neutral red (both in $50 \%$ ethanol) with $50 \mathrm{ml}$ buffer. Enzyme solutions were prepared as for trypsin.

\section{Results}

The results of the screening test to date are shown in Table I. Of the 6595 tests conducted, 3 cases of cystic fibrosis confirmed by sweat testing have been detected. One was the sib of a known case, but the laboratory processing was done by a technician unaware of this. A case of persistent (>4 months) pancreatic achylia (as shown by

\section{TABLE I}

Statistical data for screening test (as of 17 June 1975)

\begin{tabular}{l|c}
\hline & 6595 \\
Total tests & $206(31 \%)$ \\
Retests requested & $40(0.6 \%)$ \\
Abnormal retests & 141 \\
Normal retests & 25 \\
Retests not yet received & $3 \dagger$ \\
Confirmed cases of cystic fibrosis & 1 in 2198 \\
Apparent incidence & \\
\hline
\end{tabular}

^Confirmed by further bulk stool samples and sweat testing.

tOne case of persistent pancreatic achylia is also under investigation.

pancreazymin/secretin pancreatic function test) was also detected. This child had failed to thrive, but did not have the other symptoms commonly associated with pancreatic achylia. The progress of this case will be reported at a later date.

A false-positive rate of $3 \%$ was encountered on the first test, with a false-positive rate of $0.6 \%$ still apparent after the second screening test. To date we are not aware of any false-negative results. Samples of blank and test cards were punched and weighed. The results are shown in Table II.

\section{TABLE II}

Sample weights for screening test

\begin{tabular}{|c|c|c|c|}
\hline Sample & No. & $\begin{array}{c}\text { Mean weight } \\
\pm \mathrm{SD}(\mathrm{mg})\end{array}$ & $\mathbf{P}$ \\
\hline & 10 & $8 \cdot 39 \pm 0 \cdot 38$ & \}$<0.017$ \\
\hline Normals & 47 & $13 \cdot 93 \pm 4 \cdot 30$ & NS $\}<0.01$ \\
\hline Abnormals & 14 & $16 \cdot 80 \pm 3 \cdot 39$ & \\
\hline
\end{tabular}

\section{Discussion}

Our discussion must concern itself with three areas. Firstly, is the test worthwile in terms of reliability and economy? Secondly, does it compare favourably with other screening tests? And thirdly, is it worthwhile in terms of the quality and quantity of life to detect such a disease in early infancy?

On the first count some objections could be raised to our high false-positive rate and the anxiety it may induce in parents. Our standards of normality are very high, being based on other workers' findings in older infants (Barbero et al., 1966) and on the necessity of our research to define all results outside the $95 \%$ confidence limits as possibly abnormal. A false-positive rate of that same figure is usually acceptable in detecting galactosaemia-a disease with an occurrence rate in the newborn one order lower. Furthermore, it is not certain that all those with a 'false' positive test are free of symptoms. Our preliminary retrospective studies suggest that many of the children in this category do not thrive well initially. We are currently looking prospectively at this group.

Although it is said that about $10 \%$ of children with cystic fibrosis do not have pancreatic achylia (Shwachman et al., 1956) and would thus not be detected by this programme, we suspect that this apparently normal pancreatic function may be a result of misleading measurements such as the stool proteolytic activity or nonlaboratory assessment of malabsorption. Even if the $10 \%$ rate is correct, this limitation in screening would have to be accepted for the recently described alternative test for meconium albumin (Prosser et al., 1974). If a false-negative rate of about $10 \%$ should prove eventually to exist, this would imply about 1 in 35003 births, or $0.005 \%$ of all births. Prosser's false-negative rate $(8 / 20,40 \%)$ is probably too high for routine use.

At the very worst, on both technical and theoretical grounds, the initial test has a false-positive rate of $3 \%$ and a false-negative rate of $10 \%$ $(0.005 \%$ of all births). It is not entirely clear whether normal pancreatic function in the newborn period has survival value in cystic fibrosis or not. Pancreatic achylia is not however uniformly associated with a severe course of the illness (Swachman, Redmond, and Khaw, 1970).

Our second consideration, namely, is this test better than others ?, must depend on reliability, convenience, and cost. A successful sweat test in the newborn would be ideal for reliability, but it is difficult to induce a high enough sweat rate to separate normal from abnormal. The sweat 
test is also labour-intensive and quite impracticable for screening in all centres in New Zealand or in any other country with a rural area. Meconium albumin concentration has recently attracted some attention, particularly in the U.K. (Prosser et al., 1974). When an individual 'dipstix' procedure is used it is not very clear that the many observers would always be able to detect subtle differences. Quality control cannot be invested in a large number of variably motivated observers, whereas quality control in a centralized biochemical newborn screening programme is readily obtained (Robinson and Elliott, 1974). Electrophoresis of protein in a central laboratory has been postulated as a way of overcoming these possibly uncontrolled meconium estimations. These assays however require expensive and committed apparatus with limited processing ability. Its specificity, reproducibility, and sensitivity has not yet been determined.

The third consideration is whether disease progress is altered by the early institution of treatment. The classical work of Shwachman et al. (1970) indicates that over a 20-year period the mean survival time has improved from approximately 1 year to 20 years of age in a group diagnosed early in life. The quality of life in many of the survivors is good. Our New Zealand survival figures over the 10 years contemporary with the latter period of the Shwachman study do not match these improvements (in preparation) and indicate that either treatment or time of diagnosis is not as good in New Zealand. A national screening programme may help to rectify this state of affairs.

We thank the Medical Research Council of New Zealand for financial support; all those who have helped in carrying out the tests and expediting follow-ups: the technicians, Miss P. A. Smith and Miss B. Baillie, Sister M. A. Scanlon, and Mrs. J. Howard from St. Helen's Hospital, Sister M. E. Tretheway from National Women's Hospital, and the many nurses from the Auckland District Nursing Service who collected follow-up samples; and all the doctors, and parents who have co-operated in this study.

\section{REFERENCES}

Barbero, G. J., Sibinga, M. S., Marino, J. M., and Seibel, R. (1966). Stool trypsin and chymotrypsin. American fournal of Diseases of Children, 112, 536.

Gibson, L. E., and Cooke, R. E. (1959). A test for concentration of electrolytes in sweat in cystic fibrosis of the pancreas utilizing pilocarpine by iontophoresis. Pediatrics, 23, 545.

Prosser, R., Owen, H., Bull, F., Parry, B., Smerkinick, J., Goodwin, H. A., and Dathan, J. (1974). Screening for cystic fibrosis by examination of meconium. Archives of Disease in Childhood, 49, 597.

Robinson, P. G., and Elliott, R. B. (1974). Rapid semiquantitative tests for trypsin and chymotrypsin. Application to screening for cystic fibrosis, enterokinase deficiency and pancreatic hypoplasia in neonates. New Zealand Medical fournal, 79, 1024.

Robinson, P. G., Smith, P. A., and Elliott, R. B. (1975). A simple method for the determination of stool trypsin and chymotrypsin. Clinica Chimica Acta, 62, 225.

Ryley, H. C., Neale, L., Brogan, T. D., and Bray, P. T. (1974) Plasma proteins in meconium from normal infants and from babies with cystic fibrosis. Archives of Disease in Childhood, 49, 901.

Schwarz, I. L., and Thaysen, J. H. (1956). Excretion of sodium and potassium in human sweat. Fournal of Clinical Investigation, 35, 114.

Shwachman, H., Redmond, A., and Khaw, K.-T. (1970). Studies in cystic fibrosis. A report of 130 patients diagnosed under 3 months of age over a 20 year period. Pediatrics, 46, 335.

Shwachman, H., Dooley, R. R., Guilmette, F., Patterson, P. R., Weil, C., and Leubner, H. (1956). Cystic fibrosis of the pancreas with varying degrees of pancreatic insufficiency. American Fournal of Diseases of Children, 92, 347.

Correspondence to Dr. P. G. Robinson, Department of Paediatrics, School of Medicine, University of Auckland, Private Bag, Auckland, New Zealand. 